\title{
Prediction of threshold value for FGA formation
}

\author{
Aiguo Zhao, Jijia Xie, Chengqi Sun, Zhengqiang Lei, Youshi Hong* \\ State Key Laboratory of Nonlinear Mechanics, Institute of Mechanics, Chinese Academy of Sciences, Beijing 100190, PR China
}

\section{A R T I C L E I N F O}

\section{Article history:}

Received 19 January 2011

Received in revised form 8 May 2011

Accepted 26 May 2011

Available online 23 June 2011

\section{Keywords:}

Very high cycle fatigue

FGA

Crack growth threshold

Frequency effect

Stress intensity factor

\begin{abstract}
A B S T R A C T
This paper studies the formation mechanism of fine granular area (FGA) in high-strength steels and predicts the threshold value of its formation. Fatigue experiments are carried out by using rotating bending and ultrasonic fatigue testing machines on a high carbon chromium steel (GCr15) with three different heat treatments. The results show that the range of stress intensity factor at the periphery of FGA $\left(\Delta K_{\mathrm{FGA}}\right)$ keeps constant with an average value of $5.2 \mathrm{MPa} \mathrm{m}^{1 / 2}$, which is close to the traditional crack growth threshold $\left(\Delta K_{\mathrm{th}, 0}\right), 5.0 \mathrm{MPa} \mathrm{m}^{1 / 2}$. A theoretical model based on the plastic zone at crack tip is proposed to predict the value of $\Delta K_{\mathrm{FGA}}$ and the predictions are in good agreement with experimental data.
\end{abstract}

(C) 2011 Elsevier B.V. All rights reserved.

\section{Introduction}

Fatigue behavior of metallic materials in very high cycle fatigue (VHCF) regime has been a subject of growing interest for machine components to meet the demand of anti-fatigue design, life prediction and damage assessment [1,2]. A number of studies have been reported on VHCF of metallic materials such as steels, aluminum alloys, titanium alloys and magnesium alloys [3-6]. The most important phenomenon is that fatigue damage still occurs below $\sigma_{\mathrm{D}}$, the conventional fatigue limit that is defined as fatigue life $N_{\mathrm{f}}=10^{7}$, or below the traditional crack growth threshold of stress intensity factor range, $\Delta K_{\mathrm{th}, 0}$. For high-strength steels, the crack initiation site in VHCF regime changes from specimen surface to subsurface and the failure is mostly caused by interior defects, such as non-metallic inclusions and other inhomogeneities. On the facture surface, the whole region of crack initiation and early propagation exhibits a pattern of "fish-eye" and a relatively rough region with fine granular morphology often presents surround the inclusion inside fish-eye. This region is named as fine granular area (FGA) by Sakai et al. [7,8], granular-bright facet (GBF) by Shiozawa et al. $[9,10]$ and optically dark area (ODA) by Murakami [5,11]. They are the same morphology but named differently due to different instrumentation used for observation. The term of FGA is used in following text of this paper. Now it is generally accepted that the formation of FGA consumes most of the fatigue life $[3,12]$. There-

\footnotetext{
* Corresponding author. Tel.: +86 10 82543966; fax: +8610 62561284

E-mail address: hongys@imech.ac.cn (Y. Hong).
}

fore, it is of great importance to further investigate the formation mechanism of FGA.

Some models have been proposed to explain the formation of FGA, such as "hydrogen embrittlement-assisted cracking" by Murakami [5], "dispersive decohesion of spherical carbide" by Shiozawa et al. $[10,13]$ and "polygonization and debonding" by Sakai [8]. They are reasonable in some ways, but it is difficult to explain all the phenomena with one single model and the quantitative information is hardly to be predicted. In the work by Chapetti et al. $[14,15]$, it was proposed that the formation of FGA was a progress of fatigue crack initiation and it was only the region outside FGA that could be considered as a progress of "pure fatigue crack propagation". An experimental model was proposed to predict the threshold based on threshold data for crack growth of specimens containing artificial defects, and the threshold was a value depending on the magnitude of the defects. But in essential the threshold should be a constant for any specific material. Sakai et al. [7] pointed out that the value of stress intensity factor range for FGA $\Delta K_{\mathrm{FGA}}$ was close to the threshold value for stable crack propagation in SUJ2 steel, $\Delta K_{\mathrm{th}, 0}$ [7], which was the first quantitative parameter proposed regarding FGA.

Many research papers on the fatigue crack propagation near threshold are reported on aluminum alloys, titanium alloys, magnesium alloys and low-strength steels $[4,16]$. For these materials, cracks initiate from specimen surface without the pattern of FGA. On the fracture surface, the morphology change of crack initiation region is not obvious, and the mechanism of crack propagation is less discussed. It appears that FGA formation needs an inner environment and a high strength of materials. For alloys, it seems that with relatively low strength, fatigue cracks always initiate from the 


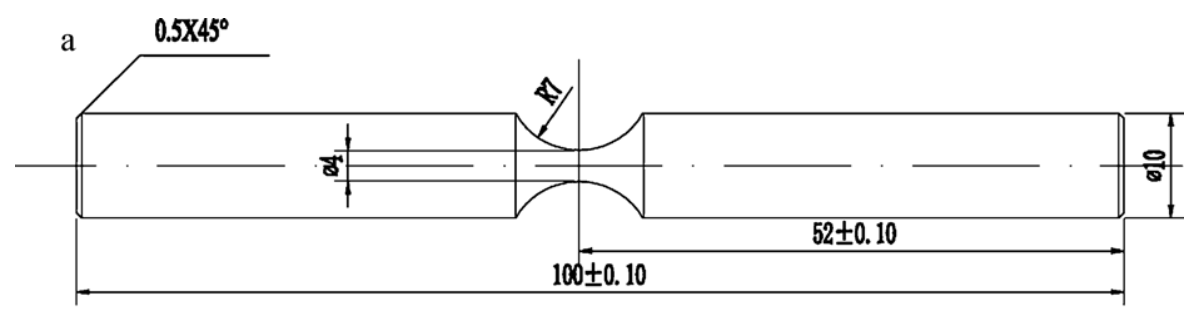

For rotating bending fatigue

b

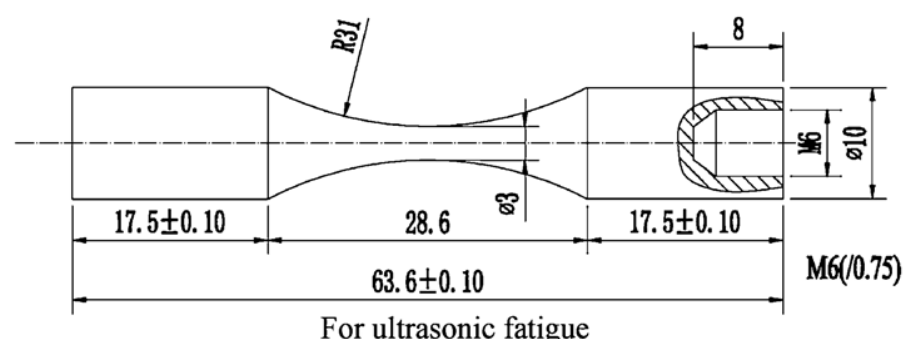

Fig. 1. Shapes and dimensions of specimens for fatigue tests.

surface, and FGA pattern is not the case. Therefore, the formation of FGA in high-strength steels may provide a unique evidence for studying crack propagation process below $\Delta K_{\mathrm{th}, 0}$.

In the present study, fatigue testing of a high carbon chromium steel (GCr15) quenched then tempered at three temperatures, was performed with rotating bending and ultrasonic fatigue testing machines to study the crack propagation behavior in the region of FGA. And a theoretical model based on the plastic zone at crack tip is proposed to predict the threshold for FGA formation and to explain the rough surface of FGA.

\section{Experimental procedure}

\subsection{Material and specimens}

The material used in this study is a high carbon chromium bearing steel (GCr15). The chemical composition (mass percentage) of this steel is: $1.01 \mathrm{C}, 1.45 \mathrm{Cr}, 0.35 \mathrm{Mn}, 0.28 \mathrm{Si}, 0.015 \mathrm{P}, 0.01 \mathrm{~S}$ and balance Fe. From the annealed steel bar, specimens were machined into hourglass shape with a certain amount of finishing margin. The specimens were heated at $845^{\circ} \mathrm{C}$ for $2 \mathrm{~h}$ in vacuum, then oilquenched and tempered for $2.5 \mathrm{~h}$ in vacuum at $150^{\circ} \mathrm{C}, 300^{\circ} \mathrm{C}$ and $450^{\circ} \mathrm{C}$ with furnace-cooling, respectively. The final geometries of specimens are shown in Fig. 1. Before fatigue testing, the round notch surface was ground and polished.

Tensile testing was conducted on MTS 810 with cylindrical specimens of $6 \mathrm{~mm}$ in diameter at a strain rate of $10^{-4} \mathrm{~s}^{-1}$. Hardness testing was performed using a Vickers hardness tester at a load of $50 \mathrm{~g}$ with a load holding time of $15 \mathrm{~s}$.

Table 1 shows the mechanical properties of the three groups of specimens. The microstructure of specimens tempered at $150^{\circ} \mathrm{C}$ is tempered martensite. From SEM photographs, it is seen that

Table 1

Mechanical properties of three groups of specimens.

\begin{tabular}{llcc}
\hline $\begin{array}{l}\text { Tempering } \\
\text { temperature } \\
\left({ }^{\circ} \mathrm{C}\right)\end{array}$ & $\begin{array}{l}\text { Micro-hardness } H_{\mathrm{v}} \\
\left(\mathrm{kgf} / \mathrm{mm}^{2}\right)\end{array}$ & \multicolumn{2}{c}{ Tensile test (MPa) } \\
\cline { 2 - 4 } & & $\sigma_{y}$ & $\sigma_{\mathrm{b}}$ \\
\hline 150 & 820 & $\mathrm{NA}$ & 2372 \\
300 & 741 & 2000 & 2150 \\
450 & 524 & 1537 & 1677 \\
\hline
\end{tabular}

small martensite blocks present, with the measured average lamellar width of $378 \mathrm{~nm}$. For specimens tempered at $300^{\circ} \mathrm{C}$ and $450^{\circ} \mathrm{C}$, the tempered martensite is rare. The prior austenite grain size is about $13.8 \mu \mathrm{m}$, obtained from 1638 grains of intergranular fatigue fracture surface of specimens tempered at $150^{\circ} \mathrm{C}$ and $300^{\circ} \mathrm{C}$.

\subsection{Fatigue testing methods}

The conventional frequency fatigue test was performed at room temperature in air by using a four-axis cantilever-type rotating bending machine, which was operated at $3150 \mathrm{rpm}(52.5 \mathrm{~Hz})$, and the stress ratio was $R=-1$. The ultrasonic fatigue testing was conducted on Shimadzu USF-2000 at a resonance frequency of $20 \mathrm{kHz}$ at room temperature in air, with a resonance interval of $100 \mathrm{~ms}$ per $500 \mathrm{~ms}$ and the stress ratio was $R=-1$. Compressive air was used to cool the specimens during ultrasonic fatigue testing. After fatigue testing, the fracture surfaces of all failed specimens were examined using a field-emission type scanning electron microscope (FE-SEM).

\section{Experimental results}

Fig. 2 represents the $S-N$ data for the three groups of specimens tested under rotating bending and ultrasonic fatigue testing. It is seen that the loading frequency has a slight effect on specimens tempered at $150^{\circ} \mathrm{C}$. While for specimens tempered at $300^{\circ} \mathrm{C}$ and $450^{\circ} \mathrm{C}$, fatigue resistance under ultrasonic loading is markedly higher than under conventional frequency loading.

Fig. 3 shows the fractography of the broken specimens. For specimens tempered at $150^{\circ} \mathrm{C}$ and $300^{\circ} \mathrm{C}$, crack initiates from the surface in low cycle regime, as shown in Fig. 3(a). In high cycle fatigue regime, crack initiates from the internal defects of specimen showing a fish-eye pattern without FGA, as shown in Fig. 3(b). And in very high cycle fatigue regime, FGA is easily observed surround the internal defects inside fish-eye, as shown in Fig. 3(c). The morphology differs for specimens tempered at $450^{\circ} \mathrm{C}$, in which fatigue crack initiates from the surface in the whole life regime under rotating bending loading. While under ultrasonic loading, fatigue crack still initiates from the interior of specimen in the long life regime, but FGA is not obvious, as shown in Fig. 3(d).

Fig. 4 illustrates the relationship between the fatigue life and the range of stress intensity factor (SIF) at the periphery of the FGA 

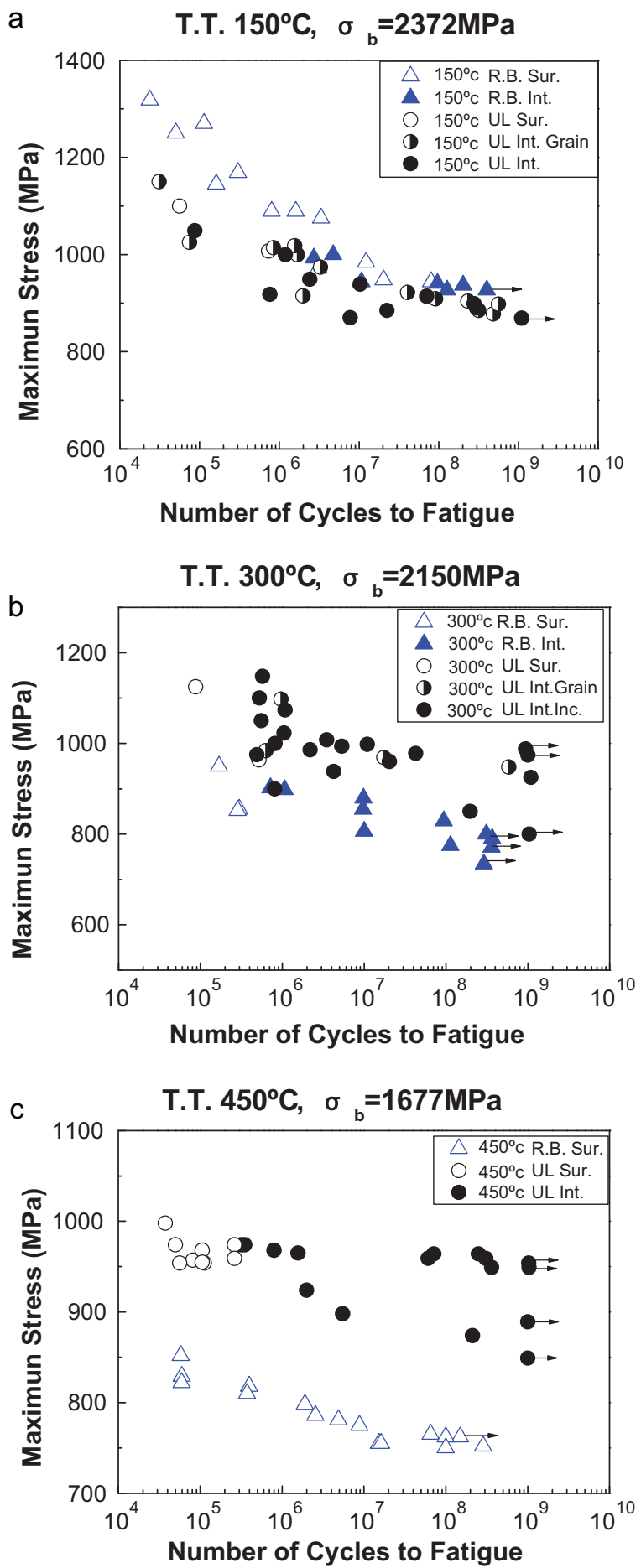

Fig. 2. $S-N$ curves under rotating bending and ultrasonic cycling for three groups of specimens, respectively (R.B.: rotating bending, UL: ultrasonic, Sur.: surface initiation, Int.: interior initiation, T.T.: tempering temperature. Symbol with arrow: no broken.).

$\left(\Delta K_{\mathrm{FGA}}\right)$ and internal inclusions $\left(\Delta K_{\mathrm{inc}}\right)$, in which $\Delta K$ is calculated by using the following equation [17]:

$\Delta K=0.5 \Delta \sigma_{a} \sqrt{\pi \sqrt{\text { area }}}$,

where $\Delta \sigma_{a}$ is stress amplitude and $\sqrt{\text { area }}$ is the size of FGA or inclusion. It is seen from Fig. 4 that the value of $\Delta K_{\text {inc }}$ tends to decrease slightly as fatigue life increases. Except for the specimens tempered at $300^{\circ} \mathrm{C}$ tested under rotating bending, $\Delta K_{\mathrm{FGA}}$ keeps almost a constant with an average of $5.2 \mathrm{MPa} \mathrm{m}^{1 / 2}$ and it is irrelevant to the tempering treatment at different temperatures and loading frequency.

From the above experiments, it is suggested that the microstructure and loading frequency may affect the behavior of crack nucleation in FGA, but it does not change the threshold value for FGA formation.

\section{Discussion}

\subsection{Characterization of FGA and its correlation with crack propagation below threshold}

It was proposed by Mughrabi [18] and Stanzl-Tschegg et al. [19] that fatigue damage still occurred at much lower stress than that caused failure and slip irreversibility was the main cause of fatigue damage in VHCF regime. Irreversible slip did exist, although small, accumulated and caused the final failure of specimens. For polycrystalline copper, Stanzl-Tschegg et al. [20] also showed that although a specimen might not break under a loading of $92 \mathrm{MPa}$ at $N=1.4 \times 10^{11}$, fatigue damage still occurred at $45 \mathrm{MPa}$ in the presence of slip bands.

The schematic of the crack growth diagram is shown in Fig. 5 , which shows three regions. Region III corresponds to unstable crack propagation leading to final fracture [7]. Region II corresponds to the stable crack propagation and crack propagation can be described by Paris law. In traditional crack propagation experiments, region I where the crack growth rate is below $10^{-10} \mathrm{~m} / \mathrm{cycle}$ is seldom discussed. It is noticed that for fatigue damage in VHCF regime, the crack propagation rate is below $10^{-10} \mathrm{~m} /$ cycle for most cases, which is correlated to the crack nucleation in FGA as shown in Fig. 3(c). In this region, how the crack propagates and when the region completes are still unclear. The traditional threshold value $\Delta K_{\mathrm{th}, 0}$ is determined by the $\Delta K$ value at the crack growth rate of $10^{-10} \mathrm{~m} /$ cycle, which corresponds to the magnitude of one Burgers vector of most metallic materials [16]. Note that if the crack propagation distance is below one lattice space during cycling, it will be easily recovered under the combination effect of lattice force and reversal loading. If the propagation distance is larger than one Burgers vector, it will be difficult to recover completely. Therefore, below and above the threshold, crack propagation rate and facture surface morphology will differ definitely.

Moreover, it is seen from Fig. 5 that the curve in region I is much steeper than that in region II, which means that in region I the crack growth rate decreases rapidly with the decrease of $\Delta K$. Further study of this region can explain how the crack initiates below the threshold. And FGA provides an exclusive evidence for such study.

The morphology of FGA is quite different from the other regions on fracture surface. Detailed study on SUJ2, a material very similar to GCr15, was carried out by Shiozawa et al. [10]. Scanning by SPM showed that the roughness on FGA region $(0.195 \mu \mathrm{m})$ was much larger than that of fish-eye region $(0.089 \mu \mathrm{m})$ outside FGA. Other studies were also carried out on JIS SKH51 [13] and SCM435 [21], which came out with similar results. In high-strength steels, the formation of FGA is very obvious and can be clearly distinguished from other regions. But for the other materials there is no clear evidence of FGA. Study by Qian et al. on $40 \mathrm{Cr}$ had shown that although there was no clearly trace of FGA surround inclusions, there was still a region whose roughness $(0.0379 \mu \mathrm{m})$ was larger than that of fish-eye region $(0.0113 \mu \mathrm{m})$ [22]. The difference of roughness is small, and maybe it is the reason why the FGA is not obvious in $40 \mathrm{Cr}$. For non-ferrous alloys, Ti-6Al-4V was the only material reported with a fracture pattern of fish-eye $[23,24]$. 


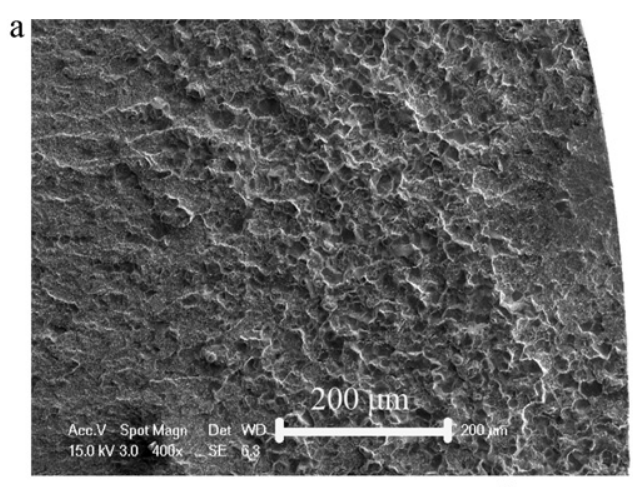

$\sigma=1270 \mathrm{MPa}, N_{f}=1.138 \times 10^{5}$

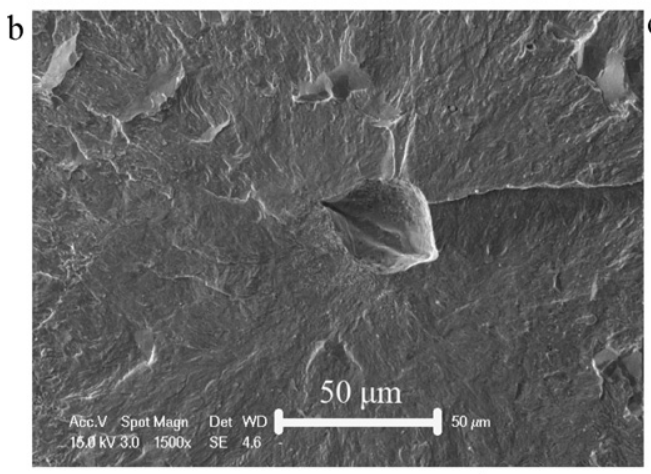

$\sigma=949 \mathrm{MPa}, N_{f}=2.408 \times 10^{6}$

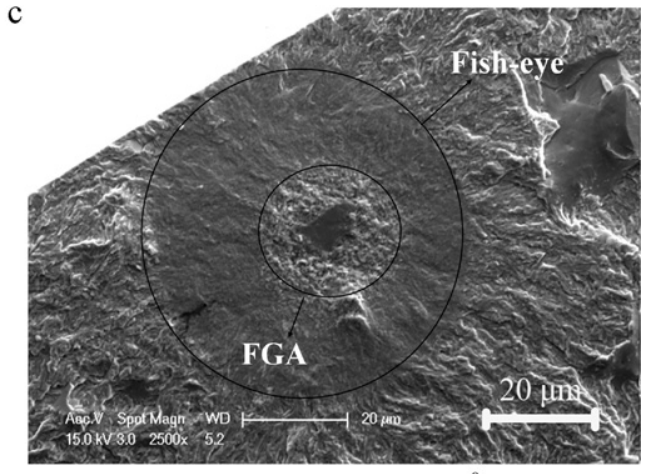

$\sigma=800 \mathrm{MPa}, N_{f}=3.103 \times 10^{8}$

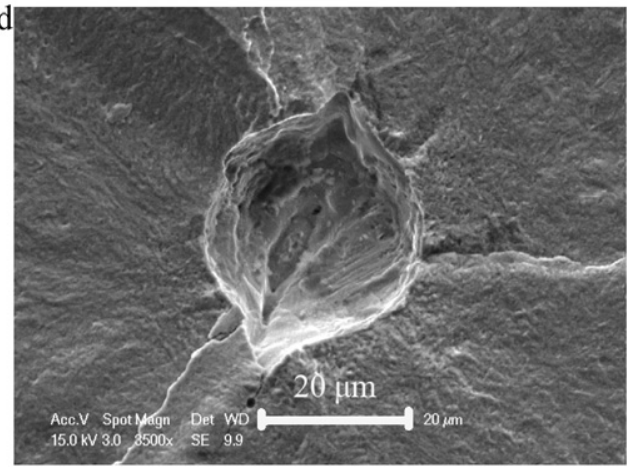

$\sigma=964 \mathrm{MPa}, N_{f}=2.504 \times 10^{8}$

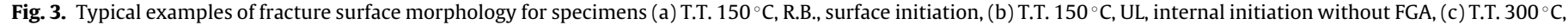
R.B., internal initiation with FGA, and (d) T.T. $450^{\circ}$ C, UL, internal initiation.

There was no area similar to FGA, but there was also a much rougher area around the initiation site than the roughness of fisheye region.

From the above discussion, it is seen that for many materials there is always a region (where the crack nucleates) different from the others (where the crack propagates stably). But it is only in highstrength steels that can this difference show clearly in the form of FGA. It is believed that the crack propagation below traditional threshold is the reason why FGA forms and displays a different morphology from the other regions. The morphology of FGA shows how the crack nucleates while the boundary explains when the initiation progress ends and when the crack begins to propagate stably.

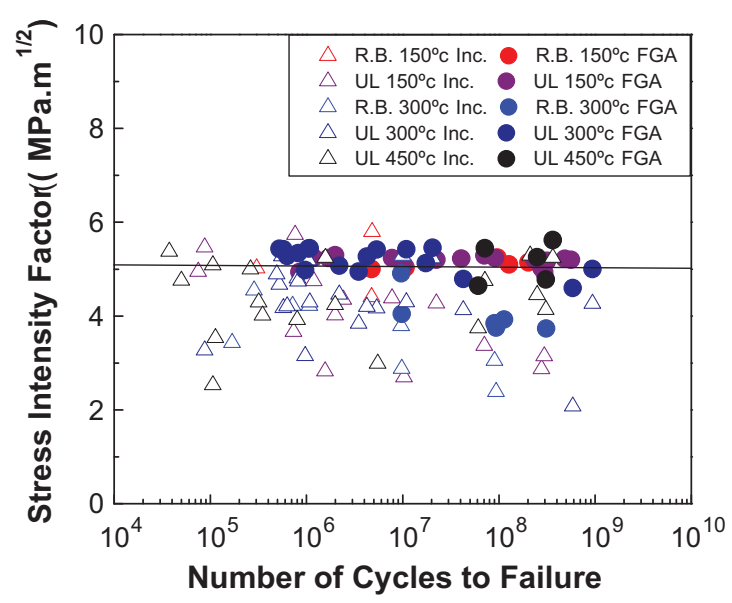

Fig. 4. Relationship between SIF range and fatigue life.

\subsection{Prediction of threshold value}

Theoretical models proposed for the formation of FGA are few till now. In this section, a model is proposed based on the plastic zone at crack tip.

For mode-I crack, the plastic zone size at the tip of crack under plain strain condition is [25]:

$r_{p}=\frac{(1-2 v)^{2}}{\pi}\left(\frac{\Delta K}{\sigma_{y}}\right)^{2} \approx \frac{1}{6 \pi}\left(\frac{\Delta K}{\sigma_{y}}\right)^{2}$

Normally, at the transition point of $d a / d N$ versus $\Delta K$ curves, the data scattering is very obvious. It is assumed that the scattering

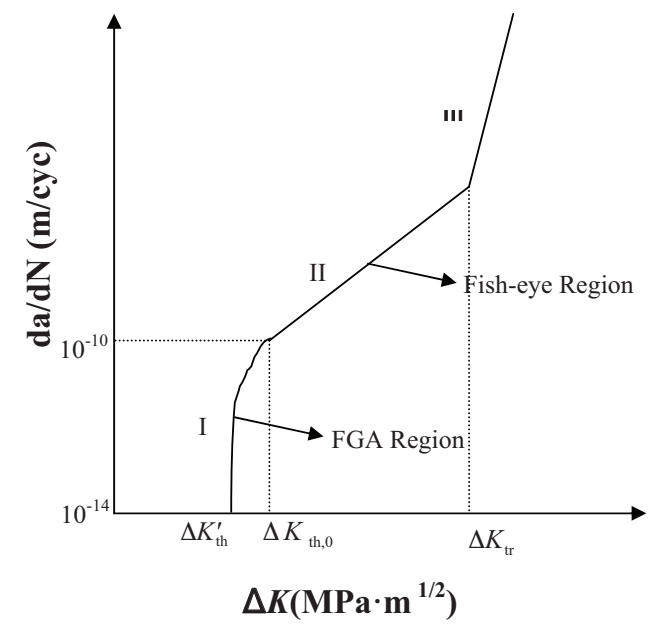

Fig. 5. Classic crack growth diagram. 
Table 2

Comparison of experimental thresholds of various steels with theoretical predictions.

\begin{tabular}{|c|c|c|c|c|c|}
\hline Materials & $\begin{array}{l}\Delta K_{\mathrm{FGA}}(\text { exp., } \\
\left.\mathrm{MPa} \mathrm{m}^{1 / 2}\right)\end{array}$ & $\begin{array}{l}\Delta K_{\text {eff,th }}(\text { exp., } \\
\mathrm{MPa} \mathrm{m}^{1 / 2} \text { ) }\end{array}$ & $\begin{array}{l}\text { Error of } \Delta K_{\mathrm{th}, 1} \\
(5.544)\end{array}$ & $\begin{array}{l}\text { Error of } \Delta K_{\mathrm{th}, 2} \\
(4.200)\end{array}$ & $\begin{array}{l}\text { Error of } \Delta K_{\mathrm{th}, 3} \\
(3.299)\end{array}$ \\
\hline GCr15 & 5.2 & & $6.62 \%$ & $-19.23 \%$ & $-36.56 \%$ \\
\hline SUJ2 [7] & 5 & $5^{*}$ & $10.88 \%$ & $-16.00 \%$ & $-34.02 \%$ \\
\hline JIS SNCM439 [28] & 5 & 4.5 & $10.88 \%$ & $-16.00 \%$ & $-34.02 \%$ \\
\hline JIS SCM435 [21] & 5.2 & & $6.62 \%$ & $-19.23 \%$ & $-36.56 \%$ \\
\hline JIS SKH51 [13] & 5.1 & & $8.71 \%$ & $-17.65 \%$ & $-35.31 \%$ \\
\hline 60Si2CrV [29] & 4.6 & & $20.52 \%$ & $-8.70 \%$ & $-28.28 \%$ \\
\hline 60Si2Mn [29] & 4.2 & & $32.00 \%$ & $0.00 \%$ & $-21.45 \%$ \\
\hline $50 \mathrm{CrV} 4$ [29] & 4.9 & & $13.14 \%$ & $-14.29 \%$ & $-32.67 \%$ \\
\hline 54SiCrV [29] & 4.9 & & $13.14 \%$ & $-14.29 \%$ & $-32.67 \%$ \\
\hline UFGS [30] & & 5.2 & $6.62 \%$ & $-19.23 \%$ & $-36.56 \%$ \\
\hline $\mathrm{X} 20 \mathrm{Cr} 13$ [31] & & $4.8(R=0)$ & $15.50 \%$ & $-12.50 \%$ & $-31.27 \%$ \\
\hline 4340 steel [30] & & 5 & $10.88 \%$ & $-16.00 \%$ & $-34.02 \%$ \\
\hline JIS G356 [32] & & $4.5(R=-1)$ & $23.20 \%$ & $-6.67 \%$ & $-26.69 \%$ \\
\hline Inconel 718 [33] & & $4.8(R=-1)$ & $15.50 \%$ & $-12.50 \%$ & $-31.27 \%$ \\
\hline 2025 steel [34] & & 4 & $38.60 \%$ & $5.00 \%$ & $-17.53 \%$ \\
\hline
\end{tabular}

${ }^{*}$ For materials whose $\Delta K_{\mathrm{FGA}}$ exist, the value of $\Delta K_{\mathrm{FGA}}$ is used for error calculation, otherwise $\Delta K_{\mathrm{eff}, \text { th }}$ is used.

is caused by random distribution of microstructure orientation: when the plastic zone size of the crack is less than the characteristic size of material, fatigue crack propagation rate will be greatly influenced by the microstructure orientation and shows great scattering. The characteristic material size of GCr15 is regard as the width of martensite lamellar $(378 \mathrm{~nm}$ ). The interior crack in FGA is considered under plain strain condition. The plastic zone size at crack front is about $220 \mathrm{~nm}$. With regard to the scattering of the microstructure parameters, the result is close to the width of martensite.

According to the work by Nix and Gao [26], a characteristic size of the material is defined as $l_{m}=b\left(\mu / \sigma_{y}\right)^{2}$. The calculated value is $304 \mathrm{~nm}$, which is close to the lamellar width of martensite. Assuming that when the plastic zone size of a crack equals to the width of martensite, the formation of FGA is completed, thus we have:

$\Delta K_{\mathrm{FGA}}=\mu \sqrt{6 \pi b}=4.342 \mu \sqrt{b}$

where $\mu$ is shear modulus, $b$ is Burgers vector. For steels, the calculated value is $5.544 \mathrm{MPa} \mathrm{m}^{1 / 2}$. It agrees well with the present experimental results of $\Delta K_{\mathrm{FGA}}, 4.5-5.5 \mathrm{MPa} \mathrm{m}^{1 / 2}$, and other results of $\Delta K_{\mathrm{th}, 0}, 5 \mathrm{MPa} \mathrm{m}^{1 / 2}$ [7]. From this model, it is seen that the value is irrelevant to the material strength and hardness, and only depends on the Burgers vector and shear modulus of material. It is verified by the experiments with the indication that the experimental value of $\Delta K_{\mathrm{FGA}}$ keeps almost a constant for specimens with different tempering treatments. How does FGA form is still unclear but now it is possible to determine when the propagation of FGA stops. That is, we are able to calculate the size of an FGA provided the stress amplitude is given.
Recently, Yang et al. [29] proposed a model to estimate the size of FGA. The model took the boundary of FGA as the place where the size of plastic zone was equal to the increment of crack growing in one stress cycle. The size of FGA was estimated as $\phi_{\mathrm{FGA}}=1240 /\left(\sigma_{y}^{0.533} \sigma^{2}\right)$, where $\phi_{\mathrm{FGA}}$ is the diameter of FGA, $\sigma_{y}$ is the yield strength of materials and $\sigma$ is the loading stress. The value of FGA is related to the yield strength of materials, which is an alternative viewpoint for the FGA size estimation.

The present model may also explain the much rougher surface of FGA. In FGA zone, crack propagation distance per cycle is lower than martensite lamellar width, so crack propagates in all directions searching for the most favorable path, and leaves a very rough fracture surface. In the fish-eye zone (outside of FGA), crack propagation distance per cycle is larger than the width of martensite lamellar, and thus crack propagates in one direction and produces a relatively smooth fracture surface.

There are two other models proposed to explain crack propagation: Weertman model [27] and Paris law. They are also adopted to predict the threshold value of FGA formation.

From the viewpoint of dislocation emission, Weertman derived a threshold SIF value below which dislocation emission was retarded [27]. Then it is proposed that an existed crack will stop propagating below the SIF value at and below which the dislocations stop emitting. The threshold is expressed as:

$\Delta K_{\mathrm{th}, \mathrm{e}} \approx 2 g E \sqrt{\frac{2 b}{5}} \approx 3.289 g \mu \sqrt{b}$

where $g$ is a constant which is unity for bcc materials and 0.6 for other materials.

Table 3

Comparison of experimental thresholds of various aluminium alloys with theoretical predictions.

\begin{tabular}{|c|c|c|c|c|}
\hline Materials & $\begin{array}{l}\Delta K_{\text {eff,th }}(\text { exp., } \\
\mathrm{MPa} \mathrm{m}^{1 / 2} \text { ) }\end{array}$ & $\begin{array}{l}\text { Error of } \Delta K_{\mathrm{th}, 1} \\
(1.911)\end{array}$ & $\begin{array}{l}\text { Error of } \Delta K_{\mathrm{th}, 2} \\
(0.8682)\end{array}$ & $\begin{array}{l}\text { Error of } \Delta K_{\mathrm{th}, 3} \\
(1.144)\end{array}$ \\
\hline $6013[16]$ & 2.1 & $-9.00 \%$ & $-58.66 \%$ & $-45.52 \%$ \\
\hline $2324[16]$ & 2 & $-4.45 \%$ & $-56.59 \%$ & $-42.80 \%$ \\
\hline $7055[16]$ & 1.5 & $27.40 \%$ & $-42.12 \%$ & $-23.73 \%$ \\
\hline $6061[16]$ & 1.5 & $27.40 \%$ & $-42.12 \%$ & $-23.73 \%$ \\
\hline $2024[16]$ & 1.7 & $12.41 \%$ & $-48.93 \%$ & $-32.71 \%$ \\
\hline AlMgSi1-T6 [35] & 2.2 & $-13.14 \%$ & $-60.54 \%$ & $-48.00 \%$ \\
\hline $7075-\mathrm{T} 6[30]$ & 2.1 & $-9.00 \%$ & $-58.66 \%$ & $-45.52 \%$ \\
\hline Cast Al-Si-Mg [36] & 2.5 & $-23.56 \%$ & $-65.27 \%$ & $-54.24 \%$ \\
\hline \multirow[t]{2}{*}{$7075-\mathrm{OA} \mathrm{[37]}$} & $2.2(R=0.05)$ & $-13.14 \%$ & $-60.54 \%$ & $-48.00 \%$ \\
\hline & $1.8(R=-1)$ & $6.17 \%$ & $-51.77 \%$ & $-36.44 \%$ \\
\hline AlZnMgCu1.5-T6 [38] & $1.8(R=-1)$ & $6.17 \%$ & $-51.77 \%$ & $-36.44 \%$ \\
\hline AlSi9Cu3 [38] & $2.8(R=-1)$ & $-31.75 \%$ & $-68.99 \%$ & $-59.14 \%$ \\
\hline E319 [39] & $1.8(R=-1)$ & $6.17 \%$ & $-51.77 \%$ & $-36.44 \%$ \\
\hline
\end{tabular}


According to Paris law, at the threshold corner [16]:

$\frac{d a}{d N}=b \quad$ and $\quad \frac{\Delta K_{\mathrm{eff}}}{E \sqrt{b}}=1$

So the following equation is assumed for the threshold:

$\Delta K_{\mathrm{eff}, \mathrm{th}}=E \sqrt{b} \approx 2.6 \mu \sqrt{b}$

Similar to Eqs. (3) and (4), this threshold is also a value only depending on shear modulus and Burgers vector.

It is seen that the similar equation is obtained by the model proposed in the present paper and those derived by Weertman model and Paris law. They are only different in coefficients. A comparison is made among the three models on many materials. For convenience, the same Burgers vector and shear modulus are used for the same type of materials in the following discussion.

For steels, $b \approx 0.25 \mathrm{~nm}, \mu \approx 81 \mathrm{GPa}$, and the predicted thresholds are presented as follows:

$$
\begin{aligned}
& \Delta K_{\mathrm{th}, 1}=\Delta K_{\mathrm{FGA}}=\mu \sqrt{6 \pi b}=4.342 \mu \sqrt{b} \approx 5.544 \mathrm{MPa} \cdot \sqrt{m} \\
& \Delta K_{\mathrm{th}, 2}=\Delta K_{\mathrm{th}, \mathrm{e}}=2 E \sqrt{0.4 b}=3.289 \mu \sqrt{b} \approx 4.200 \mathrm{MPa} \cdot \sqrt{m} \\
& \Delta K_{\mathrm{th}, 3}=\Delta K_{\mathrm{eff}, \mathrm{th}}=E \sqrt{b}=2.6 \mu \sqrt{b} \approx 3.299 \mathrm{MPa} \cdot \sqrt{m}
\end{aligned}
$$

A group of data are collected to verify the three models, as listed in Table 2 (because the size of FGA is very small, $\Delta K_{\mathrm{FGA}}$ is generally considered as effective SIF. In the column of $\Delta K_{\text {eff,th }}$, some data are not effective thresholds, so the stress ratios are clarified.).

For aluminium alloys, $b \approx 0.2863 \mathrm{~nm}, \mu \approx 26 \mathrm{GPa}$, the predicted thresholds are:

$$
\begin{aligned}
& \Delta K_{\mathrm{th}, 1}=\Delta K_{\mathrm{FGA}}=4.342 \mu \sqrt{b} \approx 1.911 \mathrm{MPa} \cdot \sqrt{m} \\
& \Delta K_{\mathrm{th}, 2}=\Delta K_{\mathrm{th}, \mathrm{e}}=1.973 \mu \sqrt{b} \approx 0.8682 \mathrm{MPa} \cdot \sqrt{m} \\
& \Delta K_{\mathrm{th}, 3}=\Delta K_{\mathrm{eff}, \mathrm{th}}=2.6 \mu \sqrt{b} \approx 1.144 \mathrm{MPa} \cdot \sqrt{m}
\end{aligned}
$$

The comparison of experimental thresholds of various aluminium alloys with theoretical predictions is shown in Table 3.

For titanium alloys, $b \approx 0.3140 \mathrm{~nm}, \mu \approx 44 \mathrm{GPa}$, the predicted thresholds are: $\Delta K_{\mathrm{th}, 1}=3.385 \mathrm{MPa} \mathrm{m}^{1 / 2}, \Delta K_{\mathrm{th}, 2}=1.538 \mathrm{MPa} \mathrm{m}^{1 / 2}$, $\Delta K_{\mathrm{th}, 3}=2.027 \mathrm{MPa} \mathrm{m}^{1 / 2}$. In some papers, it was shown that for Ti-6Al-4V, $\Delta K_{\text {eff,th }}=4 \mathrm{MPa} \mathrm{m}^{1 / 2}[30], \Delta K_{\mathrm{th}}=3.5 \mathrm{MPa} \mathrm{m}^{1 / 2}(R=-1)$ [40], $\Delta K_{\text {eff,th }}=3.4 \mathrm{MPa} \mathrm{m}^{1 / 2}[41]$.

For magnesium alloys, $b \approx 0.3186 \mathrm{~nm}, \mu \approx 18 \mathrm{GPa}$, the predicted thresholds are: $\Delta K_{\mathrm{th}, 1}=1.179 \mathrm{MPa} \mathrm{m}^{1 / 2}, \Delta K_{\mathrm{th}, 2}=0.5359 \mathrm{MPa} \mathrm{m}^{1 / 2}$, $\Delta K_{\mathrm{th}, 3}=0.7064 \mathrm{MPa} \mathrm{m}^{1 / 2}$, which can be verified by the work of other researchers [38]: AM60hp, $\Delta K_{\mathrm{th}}=1.5 \mathrm{MPa} \mathrm{m}^{1 / 2} \quad(R=-1)$; AZ91hp, $\Delta K_{\mathrm{th}}=1.4 \mathrm{MPa} \mathrm{m}^{1 / 2}(R=-1) ;$ AS21hp, $\Delta K_{\mathrm{th}}=1.3 \mathrm{MPa} \mathrm{m}^{1 / 2}$ $(R=-1)$.

From the comparisons, it is seen that the models given by Weertman and Paris have large differences with the experimental results, while the model proposed in this paper is in good agreement with most available experimental results.

\section{Conclusions}

This paper studies the formation mechanism of FGA in highstrength steels and predicts the threshold value for its formation. The experimental results show that for all the materials under rotating bending loading and ultrasonic fatigue loading, the range of SIF at the periphery of the FGA $\left(\Delta K_{\mathrm{FGA}}\right)$ keeps constant with an average value of $5.2 \mathrm{MPa} \mathrm{m}{ }^{1 / 2}$ except that of specimens tempered at $300^{\circ} \mathrm{C}$ under rotating bending loading. The range of SIF at the periphery of the FGA $\left(\Delta K_{\mathrm{FGA}}\right)$ is close to the traditional crack growth threshold, $\Delta K_{\mathrm{th}, 0}$. It is revealed that the crack initiation process in FGA corresponds to the crack propagation in region I below $\Delta K_{\mathrm{th}, 0}$. A theoretical model based on the plastic zone at crack tip is proposed to predict $\Delta K_{\mathrm{FGA}}$ or $\Delta K_{\mathrm{th}, 0}$, which depends only on the Burgers vector and the shear modulus of material. The model also explains the rough surface of FGA and the predictions agree with the experiments. Two other models based on cracks propagation, Weertman model and Paris model, are also adopted to predict the threshold value of FGA formation. A comparison is made among the three models and the results show that the model proposed based on plastic zone at crack tip is in accordance with the experiments.

\section{Acknowledgements}

This paper was supported by the National Natural Science Foundation of China (nos. 10772178 and 10721202) and the Knowledge Innovation Program of the Chinese Academy of Sciences (no. KJCX2YW-L07).

\section{References}

[1] I. Marines, X. Bin, C. Bathias, Int. J. Fatigue 25 (2003) 1101-1107.

[2] C. Bathias, L. Drouillac, P. Le Francois, Int. J. Fatigue 23 (2001) 143-151.

[3] Q.Y. Wang, J.Y. Berard, A. Dubarre, G. Baudry, S. Rathery, C. Bathias, Fatigue Fract. Eng. Mater. Struct. 22 (1999) 667-672.

[4] C. Bathias, P.C. Paris, Gigacycle Fatigue in Mechanical Practice, Marcel Dekker, New York, 2005.

[5] Y. Murakami, Metal Fatigue: Effects of Small Defects and Nonmetallic Inclusions, Elsevier, Oxford, 2002.

[6] C.E. Zhou, G.A. Qian, Y.S. Hong, Key Eng. Mater. 324-325 (2006) 1113-1116.

[7] T. Sakai, Y. Sato, N. Oguma, Fatigue Fract. Eng. Mater. Struct. 25 (2002) 765-773.

[8] T. Sakai, in: J.E. Allison, J.W. Jones, J.M. Larsen, R.O. Ritchie (Eds.), Fourth International Conference on Very High Cycle Fatigue (VHCF-4), University of Michigan, 2007, pp. 3-12.

[9] K. Shiozawa, L. Lu, S. Ishihara, Fatigue Fract. Eng. Mater. Struct. 24 (2001) 781-790.

[10] K. Shiozawa, Y. Morii, S. Nishino, L. Lu, Int. J. Fatigue 28 (2006) 1521-1532.

[11] Y. Murakami, T. Nomoto, T. Ueda, Fatigue Fract. Eng. Mater. Struct. 22 (1999) 581-590.

[12] I. Marines-Garcia, P.C. Paris, H. Tada, C. Bathias, Mater. Sci. Eng. A 468-470 (2007) 120-128.

[13] K. Shiozawa, Y. Morii, S. Nishino, JSME Int. J. Ser. A-Solid Mech. Mater. Eng. 49 (2006) 1-10.

[14] M.D. Chapetti, T. Tagawa, T. Miyata, Mater. Sci. Eng. A 356 (2003) 227-235

[15] M.D. Chapetti, T. Tagawa, T. Miyata, Mater. Sci. Eng. A 356 (2003) 236-244.

[16] P.C. Paris, H. Tada, J.K. Donald, Int. J. Fatigue 21 (1999) S35-S46.

[17] Y. Murakami, S. Kodama, S. Konuma, Trans. Jpn. Soc. Mech. Eng. 54 (1988) 688-695.

[18] H. Mughrabi, Int. J. Fatigue 28 (2006) 1501-1508.

[19] S. Stanzl-Tschegg, H. Mughrabi, B. Schoenbauer, Int. J. Fatigue 29 (2007) 2050-2059.

[20] S.E. Stanzl-Tschegg, B. Schönbauer, Int. J. Fatigue 32 (2010) 886-893.

[21] Y. Murakami, T. Nomoto, T. Ueda, Fatigue Fract. Eng. Mater. Struct. 23 (2000) 903-910

[22] G.A. Qian, Y.S. Hong, C.E. Zhou, Eng. Failure Anal. 17 (2010) 1517-1525.

[23] E. Takeuchi, Y. Furuya, N. Nagashima, S. Matsuoka, Fatigue Fract. Eng. Mater. Struct. 31 (2008) 599-605.

[24] A.J. McEvily, T. Nakamura, H. Oguma, K. Yamashita, H. Matsunaga, M. Endo, Scripta Mater. 59 (2008) 1207-1209.

[25] R.W. Hertzberg, Deformation Fracture Mechanics of Engineering Materials, 4th ed., Wiley, 1995.

[26] W.D. Nix, H.J. Gao, J. Mech. Phys. Solids 46 (1998) 411-425.

[27] J. Weertman, in: J. Weertman (Ed.), Fatigue crack growth in ductile metals, The American Society of Mechanical Engineers, Washington, DC, 1981.

[28] Y. Ochi, T. Matsumura, K. Masaki, S. Yoshida, Fatigue Fract. Eng. Mater. Struct. 25 (2002) 823-830.

[29] Z.G. Yang, S.X. Li, Y.B. Liu, Y.D. Li, G.Y. Li, W.J. Hui, Y.Q. Weng, Int. J. Fatigue 30 (2008) 1016-1023.

[30] X.P. Huang, T. Moan, Int. J. Fatigue 29 (2007) 591-602

[31] S.E. Stanzl-Tchegg, Fatigue Fract. Eng. Mater. Struct. 22 (1999) 567-579.

[32] Y. Akiniwa, S. Stanzl-Tschegg, H. Mayer, M. Wakita, K. Tanaka, Int. J. Fatigue 30 (2008) 2057-2063.

[33] Q. Chen, N. Kawagoishi, Q.Y. Wang, N. Yan, T. Ono, G. Hashiguchi, Int. J. Fatigue 27 (2005) 1227-1232.

[34] H.L. Huang, N.J. Ho, Mater. Sci. Eng. A 334 (2002) 134-140.

[35] L.P. Borrego, J.M. Costa, S. Silva, J.M. Ferreira, Int. J. Fatigue 26(2004)1321-1331.

[36] D.A. Lados, D. Apelian, J.K. Donald, Acta Mater. 54 (2006) 1475-1486.

[37] B. Holper, H. Mayer, A.K. Vasudevan, S.E. Stanzl-Tschegg, Int. J. Fatigue 26 (2004) 27-38.

[38] M. Papakyriacou, H. Mayer, U. Fuchs, S.E. Stanzl-Tschegg, R.P. Wei, Fatigue Fract. Eng. Mater. Struct. 25 (2002) 795-804.

[39] X. Zhu, J.Z. Yi, J.W. Jones, J.E. Allison, in: J.E. Allison, J.W. Jones, J.M. Larsen, R.O. Ritchie (Eds.), Fourth International Conference on Very High Cycle Fatigue (VHCF-4), University of Michigan, 2007, pp. 325-429.

[40] J. Petit, C. Sarrazin-Baudoux, Int. J. Fatigue 28 (2006) 1471-1478.

[41] R.O. Ritchie, D.L. Davidson, B.L. Boyce, J.P. Campbell, O. Roder, Fatigue Fract. Eng. Mater. Struct. 22 (1999) 621-631. 